\title{
Antithrombotic therapy for long-term secondary prevention of acute coronary syndrome in high-risk patients
}

This article was published in the following Dove Press journal:

Therapeutics and Clinical Risk Management

17 February 2015

Number of times this article has been viewed

\author{
Steen Husted ${ }^{1,2}$ \\ 'Department of Biomedicine, Centre \\ for Clinical Pharmacology, Aarhus, \\ ${ }^{2}$ Department of Medicine, Hospital \\ Unit West, Herning, Denmark
}

\begin{abstract}
Patients with acute coronary syndrome (ACS) represent a major clinical burden, because they tend to experience recurrent ischemic events. Acute management of patients with ACS includes combination antithrombotic therapy composed of a parenteral anticoagulant and dual-antiplatelet therapy. Dual-antiplatelet therapy is also recommended for long-term secondary prevention of ACS. Despite advances in the antithrombotic therapies available, clinical trials suggest that patients with ACS still face a $\sim 10 \%$ risk of another event within 12-15 months of the index event. Certain patient populations, such as elderly patients and those with renal impairment or heart failure, are at higher risk of recurrent ACS events, because these patients have more vascular ischemic and bleeding risk factors than most other patients. Evidence from the GRACE and CRUSADE registries suggests underuse of the guideline-recommended evidencebased therapies for the management of ACS in such patients. This review summarizes the current standard of care for patients with ACS, focusing on long-term secondary antithrombotic strategies. Registry data are used to identify high-risk patient populations; the recent antiplatelet and anticoagulant Phase III trial data are summarized to highlight any patient populations who receive greater or lesser benefit from specific long-term antithrombotic strategies. Guideline recommendations are discussed and suggestions are provided to help improve implementation of long-term secondary prevention strategies and patient prognosis after an ACS event.
\end{abstract}

Keywords: acute coronary syndrome, anticoagulants, antiplatelets, risk assessment, secondary prevention

\section{Introduction}

Coronary artery disease (CAD) accounts for approximately 30\% of all deaths from cardiovascular causes, and atherosclerotic plaque disruption with subsequent thrombus formation is the leading cause of an acute coronary syndrome (ACS) event. ${ }^{1} \mathrm{ACS}$, which encompasses ST-segment elevation myocardial infarction (STEMI), nonST-segment elevation myocardial infarction (NSTEMI), and unstable angina (UA), represents a major clinical burden. ${ }^{2}$ Post-hospital discharge mortality rates in Europe indicate that a substantial number of patient deaths will be caused by a recurrent ischemic event within 6 months of the index ACS event $(4.8 \%, 6.2 \%$, and $3.6 \%$ of patients with STEMI, NSTEMI, and UA, respectively), ${ }^{3}$ highlighting that all types of ACS are serious. STEMI is associated with the highest in-hospital mortality rate of the three conditions, whereas NSTEMI has the highest post-hospital discharge mortality rate (Figure 1); however, most ACS-related deaths occur after hospital discharge, regardless of ACS type $\left(68 \%, 86 \%\right.$, and $97 \%$ for STEMI, NSTEMI, and UA, respectively). ${ }^{2}$ Additionally, the incidence of ACS-related mortality is predicted to rise as the elderly proportion of the population increases in size. ${ }^{4}$
Department of Medicine, Hospital Unit

West, 6 I GI Landevej, Herning 7400,

Denmark

Tel +45 24299963

Email steehust@rm.dk 
A

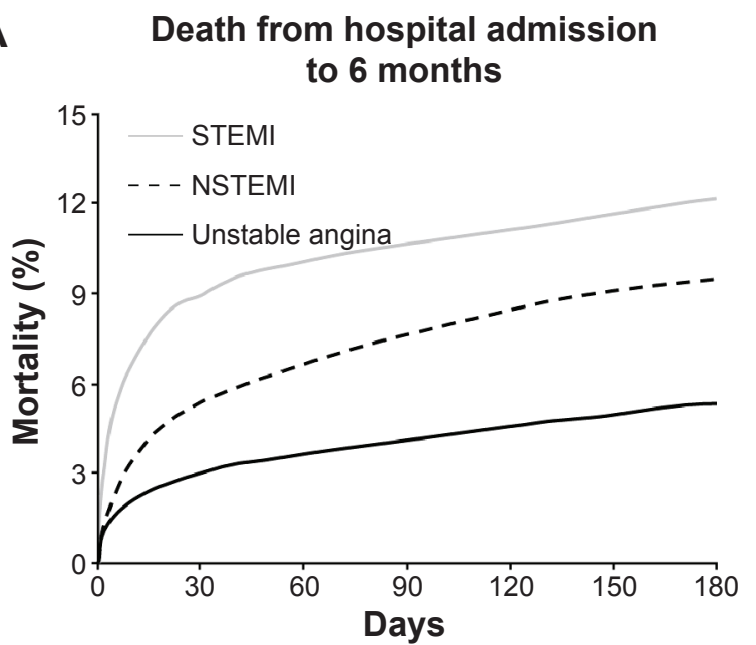

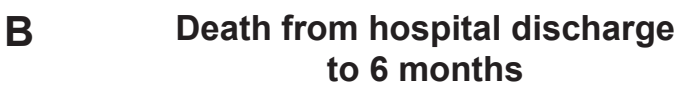

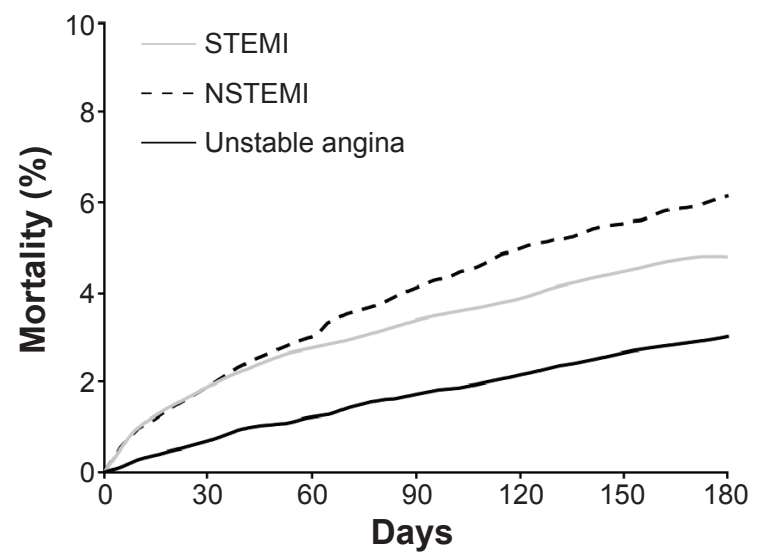

Figure I Six-month mortality data from the Global Registry of Acute Coronary Events (GRACE).

Notes: Data evaluate 43,810 patients with acute coronary syndrome, and demonstrate that after discharge for an acute ischemic event (with either hospital admission [A] or hospital discharge [B] as a starting point), mortality rates remain high. Reproduced from Prediction of risk of death and myocardial infarction in the six months after presentation with acute coronary syndrome: prospective multinational observational study (GRACE), Fox KA, Dabbous OH, Goldberg RJ, et al, 333(7578), I09I, @ 2006 with permission from BMJ Publishing Group Ltd. ${ }^{20}$

Abbreviations: NSTEMI, non-ST-segment elevation myocardial infarction; STEMI, ST-segment elevation myocardial infarction.

In addition to coronary reperfusion or revascularization, current standard therapy for ACS in the acute phase includes combination antithrombotic therapy, consisting of a parenteral anticoagulant and dual-antiplatelet therapy (DAPT) with acetylsalicylic acid (ASA) plus a $\mathrm{P}_{2} \mathrm{Y}_{12}$ inhibitor. For longterm secondary prevention of ACS, DAPT alone is generally recommended to reduce bleeding risk. ${ }^{5,6}$ Numerous studies have reported antiplatelet failure and variability in antiplatelet efficacy, with some patients being identified as low or nonresponders to ASA or clopidogrel therapy. ${ }^{7}$ However, controversy exists regarding antiplatelet resistance, which could be caused by genetic polymorphisms affecting target proteins ${ }^{7}$ another hypothesis is patient adherence (compliance) to therapy. ${ }^{8}$ Patients who exhibit a degree of antiplatelet resistance remain at a high risk of ischemic events, owing to insufficient inhibition of platelets, ${ }^{8}$ but further evidence is required to establish a need for platelet function and genotype testing in the clinic. ${ }^{9}$

Advances in the management of patients with ACS in recent years include the advent of the newer antiplatelet agents prasugrel and ticagrelor. Despite these advances, however, clinical trials with prasugrel and ticagrelor report that there remains a residual risk of approximately $10 \%$ for recurrent cardiovascular events for the subsequent $12-15$ months after an ACS event, a statement true for patients with STEMI and patients with non-ST-segment elevation acute coronary syndrome (NSTE-ACS). ${ }^{10,11}$ However, the assumption that all patients with ACS are at equal risk of recurrent ischemic events cannot be made: certain patient populations are considered at higher risk because they have more ischemic risk factors. ${ }^{5}$
Indeed, data show that a treatment gap exists in the long-term secondary prevention of ACS in high-risk patients. ${ }^{12-17}$

This review summarizes the current standard of care for patients with ACS, focusing on long-term secondary antithrombotic strategies. Registry data and recent antiplatelet and anticoagulant Phase III trial data are used to highlight any patient populations who receive greater or lesser benefit from specific long-term antithrombotic strategies. Guideline recommendations are discussed, and suggestions are provided to help improve implementation of long-term secondary prevention strategies and patient prognosis after an ACS event. A simple PubMed literature search of papers published between 2000 and 2014 using search terms encapsulated within the area of antithrombotic therapy, clinical trials, registries, and high-risk patient populations was carried out to identify the relevant data discussed here.

\section{Antithrombotic treatment strategies: current standard of care Treatment in the acute phase}

For patients with STEMI, the principal recommendation in European guidelines for the acute-management phase is early reperfusion therapy using percutaneous coronary intervention (PCI) with stenting, or fibrinolytic treatment if early PCI cannot be offered, followed by consideration of rescue PCI. The recommended periprocedural antithrombotic therapy in these patients is DAPT and a parenteral anticoagulant (bivalirudin, unfractionated heparin, or lowmolecular-weight heparin) with or without a glycoproteinreceptor blocker. ${ }^{6}$ 
For patients with NSTE-ACS, acute management also includes DAPT for 12 months to reduce the risk of acute ischemic complications and prevent recurrent ischemic events. ${ }^{5}$ In addition to antiplatelet therapy, a therapeutic dose of anticoagulation is recommended during the acute in-hospital phase to inhibit thrombin formation and reduce thrombusrelated events. ${ }^{5}$ Patients with NSTE-ACS at moderate-to-high risk of recurrent ischemic events will require an invasive strategy, such as PCI; in this instance, guidelines recommend intervention within 24 hours in high-risk patients and no later than 72 hours after presentation in all patients requiring intervention, after which discontinuation of anticoagulation should be considered. ${ }^{5,18}$ If for one reason or another the intervention is postponed, anticoagulation is advised to prevent further ischemic events; for patients with NSTE-ACS, the risk of bleeding related to surgery must be balanced with the risk of recurrent ischemic events. ${ }^{5}$

\section{Long-term secondary prevention}

Advances in treatment options for patients with ACS have had a substantial impact in terms of improved survival and prognosis after an index ACS event, particularly in the short-term/acute phase. ${ }^{19}$ However, as noted earlier, many patients remain at risk of further events or death in the months and years after they are discharged from hospital (Figure 1). ${ }^{10,11,20}$ Further advances are required to improve long-term patient prognosis.

After hospital discharge, long-term secondary prevention strategies are similar for STEMI and NSTE-ACS, and until very recently, they consisted of DAPT alone for up to 1 year. ${ }^{5,6}$ Long-term anticoagulant therapy on top of DAPT is not recommended, because of a lack of clear clinical benefit and concerns over increased bleeding. ${ }^{21}$ However, there is a clear mechanistic justification for adding anticoagulant therapy to DAPT in the long-term secondary prevention phase: arterial thrombi are composed of both platelets and fibrin. Thrombin has an important role in both platelet activation (acting as an agonist of platelet activation and aggregation) and fibrin formation (catalyzing the conversion of fibrinogen to fibrin), which constitute the dual pathway of thrombus formation. ${ }^{22}$ Studies have shown that excess thrombin generation remains for 6-12 months after the index ACS event, meaning that it extends well beyond the acute setting. ${ }^{23}$ This may explain the potential benefit of a combined antiplatelet and anticoagulant approach in the long-term secondary prevention setting.

The ATLAS ACS 2 TIMI 51 trial was designed to assess the effect of rivaroxaban, an oral, direct factor Xa inhibitor, in the prevention of further ischemic events when combined with DAPT in patients stabilized after an ACS event. ${ }^{24}$ The findings of the trial (efficacy results summarized in Figure 2) led to the European approval of rivaroxaban $2.5 \mathrm{mg}$ twice daily in combination with ASA alone or ASA plus clopidogrel or ticlopidine for 12 months in patients after an ACS event who have elevated cardiac biomarkers and no history of prior stroke/transient ischemic attack (TIA). ${ }^{25}$ Indeed, the most recent European Society of Cardiology STEMI guidelines state that in selected patients with low bleeding risk, oral anticoagulation with rivaroxaban $2.5 \mathrm{mg}$ twice daily may be considered in patients who receive ASA and clopidogrel. ${ }^{6}$ Guideline updates on the possible use of rivaroxaban in patients with NSTEMI or UA are awaited.

Recent Phase $11^{26,27}$ and Phase III ${ }^{10,11,24,28-31}$ clinical trials (Phase III trials summarized in Table 1) of the newer antiplatelets and non-vitamin K-antagonist oral anticoagulants $(\mathrm{NOACs})^{32}$ have investigated their potential for secondary prevention of ischemic events after an ACS event. Relative to the respective standards of care, or placebo in the case of rivaroxaban, ticagrelor, prasugrel, and rivaroxaban demonstrated favorable benefit-risk profiles, with similar or improved efficacy rates and acceptable bleeding rates. The newer antiplatelets and NOACs are discussed herein in detail, with the exception of apixaban, darexaban, and dabigatran. In the Phase II ATLAS ACS TIMI 46 trial, the safety and efficacy of a wide variety of rivaroxaban doses were assessed; this led to the evaluation of two dosing strategies (rivaroxaban $2.5 \mathrm{mg}$ twice daily and $5 \mathrm{mg}$ twice daily) in the Phase III ATLAS ACS 2 TIMI 51 trial. ${ }^{24}$ In the APPRAISE 2 trial, apixaban demonstrated a high bleeding risk and lack of benefit, and the trial was terminated prematurely. ${ }^{28} \mathrm{Nei}-$ ther dabigatran nor darexaban has been tested in a Phase III trial in ACS. DAPT of ASA plus clopidogrel, ticagrelor, or prasugrel has become the standard care for ACS. ${ }^{5,6}$

Most patients with ACS have comorbidities or conditions that affect their overall benefit-risk profile, because such factors can affect ischemic or bleeding risks. 5,6 These factors must be taken into consideration when deciding on a patient's antithrombotic treatment regimen. High-risk patient populations are generally underrepresented in trials compared with the real-world situation, and some ambiguity remains regarding which antithrombotic strategies provide the greatest benefit in the different high-risk patient populations. ${ }^{33}$

Direct comparisons cannot be made between trial data, because of the variability in patient populations, treatment arms, outcome definitions, and other methodological considerations. However, for each high-risk patient population, the relative benefits and risks can be assessed through subgroup analysis, in which trial data are available. Key differences between high-risk and non-high-risk populations are discussed in the relevant following sections. 


\begin{tabular}{|c|c|c|c|c|c|}
\hline \multirow[t]{2}{*}{ Subgroup } & $\begin{array}{l}\text { Combined } \\
\text { rivaroxaban }\end{array}$ & Placebo & $\begin{array}{l}\text { HR } \\
(95 \% \mathrm{Cl})\end{array}$ & $\begin{array}{l}\text { HR } \\
(95 \% \mathrm{Cl})\end{array}$ & \multirow{2}{*}{$\begin{array}{l}P \text {-value } \\
\text { for } \\
\text { interaction }\end{array}$} \\
\hline & \multicolumn{2}{|l|}{$\begin{array}{l}\text { No of events/ } \\
\text { total no }\end{array}$} & & & \\
\hline Overall & $626 / 10,229$ & $376 / 5,113$ & $0.84(0.74-0.96)$ & & \multirow{3}{*}{0.34} \\
\hline Tx: ASA + thienopyridine & $575 / 9,532$ & $340 / 4,760$ & $0.86(0.75-0.98)$ & & \\
\hline ASA alone & $51 / 697$ & $36 / 353$ & $0.69(0.45-1.05) \leftarrow$ & & \\
\hline Age: $<65$ years & $326 / 6,440$ & $203 / 3,295$ & $0.83(0.70-0.99)$ & & \multirow{2}{*}{0.94} \\
\hline$\geq 65$ years & $300 / 3,789$ & $173 / 1,818$ & $0.84(0.70-1.01)$ & & \\
\hline Sex: Male & $464 / 7,627$ & $270 / 3,831$ & $0.87(0.75-1.01)$ & & \multirow{2}{*}{0.40} \\
\hline Female & $162 / 2,602$ & $106 / 1,282$ & $0.77(0.60-0.99)$ & & \\
\hline Weight: $<60 \mathrm{~kg}$ & $61 / 918$ & $39 / 462$ & $0.83(0.56-1.25)$ & & \multirow{3}{*}{0.98} \\
\hline$\geq 60$ to $<90 \mathrm{~kg}$ & $415 / 6,811$ & $248 / 3,432$ & $0.85(0.72-0.99)$ & & \\
\hline$\geq 90 \mathrm{~kg}$ & $150 / 2,494$ & $89 / 1,215$ & $0.83(0.64-1.08)$ & & \\
\hline \multirow{2}{*}{$\begin{aligned} \mathrm{CrCl}: & <50 \mathrm{~mL} / \mathrm{min} \\
& \geq 50 \mathrm{~mL} / \mathrm{min}\end{aligned}$} & $80 / 686$ & $49 / 368$ & $0.88(0.62-1.26)$ & & \multirow{2}{*}{0.82} \\
\hline & $541 / 9,411$ & $326 / 4,691$ & $0.84(0.73-0.96)$ & & \\
\hline \multirow{2}{*}{$\begin{array}{r}\text { Previous MI: Yes } \\
\text { No }\end{array}$} & $256 / 2,739$ & $156 / 1,400$ & $0.83(0.68-1.01)$ & & \multirow{2}{*}{0.80} \\
\hline & $370 / 7,490$ & $220 / 3,713$ & $0.85(0.72-1.01)$ & & \\
\hline \multirow{2}{*}{$\begin{array}{r}\text { Previous stroke/TIA: Yes } \\
\text { No }\end{array}$} & $31 / 284$ & $9 / 131$ & $1.57(0.75-3.31)$ & & \multirow{2}{*}{0.10} \\
\hline & $595 / 9,945$ & $367 / 4,982$ & $0.82(0.72-0.94)$ & & \\
\hline Diabetes mellitus: Yes & $232 / 3,268$ & $122 / 1,626$ & $0.96(0.77-1.20)$ & & \multirow{2}{*}{0.14} \\
\hline No & $394 / 6,961$ & $254 / 3,487$ & $0.78(0.67-0.92)$ & & \\
\hline Index event: STEMI & $288 / 5,128$ & $172 / 2,599$ & $0.85(0.70-1.03)$ & & \multirow{3}{*}{0.96} \\
\hline NSTEMI & $201 / 2,646$ & $121 / 1,321$ & $0.85(0.68-1.06)$ & & \\
\hline UA & $137 / 2,455$ & $83 / 1,193$ & $0.82(0.62-1.07)$ & & \\
\hline Region: North America & $27 / 562$ & $27 / 312$ & $0.57(0.33-0.97) \leftarrow$ & & \multirow{6}{*}{0.80} \\
\hline South America & $64 / 1,129$ & $35 / 540$ & $0.89(0.59-1.34)$ & & \\
\hline Western Europe & $59 / 1,482$ & $34 / 759$ & $0.90(0.59-1.37)$ & & \\
\hline Eastern Europe & $306 / 4,067$ & $181 / 2,007$ & $0.83(0.69-1.00)$ & & \\
\hline Asia & $109 / 2,011$ & $65 / 1,000$ & $0.86(0.63-1.17)$ & $\stackrel{1}{1}$ & \\
\hline \multirow[t]{2}{*}{ Other } & $61 / 978$ & $34 / 495$ & $0.92(0.60-1.39)$ & $i$ & \\
\hline & & & 0.5 & $0.8 \quad 1.0 \quad 1.25$ & 2.0 \\
\hline
\end{tabular}

Figure 2 The ATLAS ACS 2 TIMI 5 I primary efficacy end point (death from cardiovascular causes, myocardial infarction, or stroke) according to patient-subgroup populations.

Note: From N Engl J Med, Mega JL, Braunwald E, Wiviott SD, et al. Rivaroxaban in patients with a recent acute coronary syndrome, 366(I), 9-19. Copyright (C) (20I2) Massachusetts Medical Society. Reprinted with permission from Massachusetts Medical Society. ${ }^{24}$

Abbreviations: ASA, acetylsalicylic acid; Cl, confidence interval; $\mathrm{CrCl}$, creatinine clearance; HR, hazard ratio; MI, myocardial infarction; NSTEMI, non-ST-segment elevation myocardial infarction; STEMI, ST-segment elevation myocardial infarction; TIA, transient ischemic attack; Tx, treatment; UA, unstable angina.

\section{High-risk patient populations with acute coronary syndrome and the treatment gap in long-term secondary prevention strategies}

The Global Registry of Acute Coronary Events (GRACE) score is used to identify the risk of ischemic events, ${ }^{20}$ and the CRUSADE (Can Rapid risk stratification of Unstable angina Suppress ADverse outcomes with Early implementation of the ACC/AHA guidelines) score is used to determine the risk of major in-hospital bleeding events. ${ }^{34}$ Risk stratification using such scores as these provides insight into which patient populations are at high risk. ${ }^{12-14,16,17}$ In these patients, there is considerable overlap between ischemic and bleeding risk factors, such as advancing age, renal impairment, and heart failure (HF) ${ }^{5,6}$ Additionally, a patient's electrocardiogram and troponin levels are important components of early risk stratification and prognosis. ${ }^{5,6}$ The identification of these 


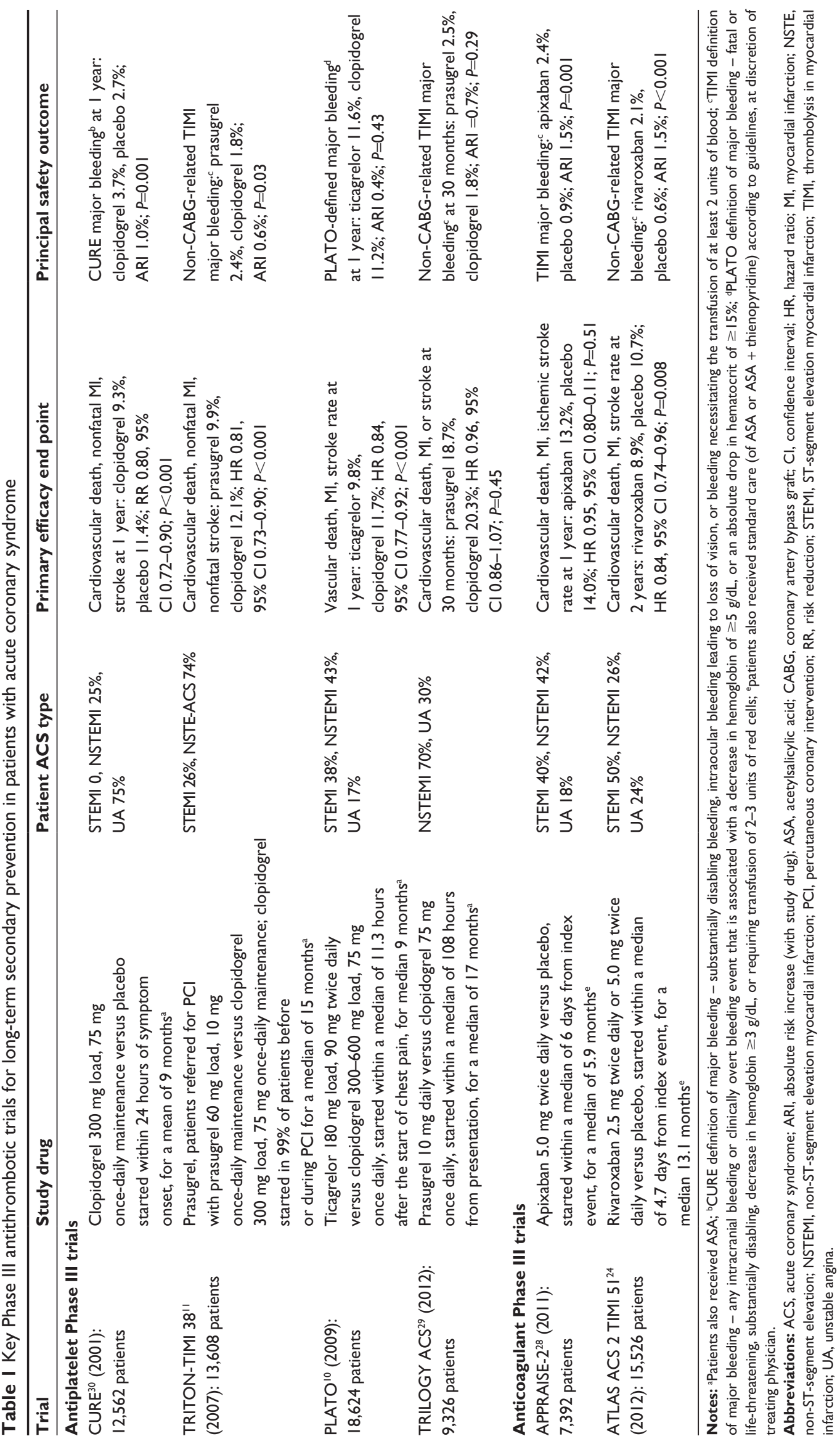


high-risk patients is critical, because studies show that in some cases, they are less likely to receive evidence-based guideline-recommended therapies compared with patients with uncomplicated ACS. ${ }^{35}$ The specific guideline recommendations for the identified high-risk patient populations discussed in the following sections are summarized in Table 2.

\section{Elderly patients}

Elderly patients ( $\geq 75$ years old) have an increased risk of recurrent ischemic events, bleeding, and mortality; currently, $60 \%$ of all ACS-related deaths are in this age-group, and this statistic is expected to rise as the proportion of the population that is elderly rises. ${ }^{36}$ Elderly patients with ACS often present atypically, which can delay diagnosis, and they may have comorbidities complicating their ACS, such as $\mathrm{HF}$, diabetes mellitus, history of stroke, renal impairment, or atrial fibrillation (AF). ${ }^{36-38}$

Elderly patients are less likely to receive therapies associated with increased bleeding risk. These include antiplatelet and anticoagulant therapies associated with increased risk of intracranial hemorrhage ( $\mathrm{ICH}),{ }^{5,13,38}$ such as prasugrel, which is not generally recommended over clopidogrel for use in elderly patients, because TRITON-TIMI 38 found that prasugrel was not associated with a net clinical benefit in patients aged $\geq 75$ years (hazard ratio [HR] $0.99,95 \%$ confidence interval [CI] $0.81-1.21 ; P=0.92) .{ }^{11,39}$

In general, with the exception of prasugrel (as mentioned earlier), data from the long-term secondary ACS-prevention trials do not suggest a substantial difference in the efficacy or safety benefits of antithrombotic agents between elderly patients and younger patients receiving the same therapy. ${ }^{24,28,30,40}$ In ATLAS ACS 2 TIMI 51, rivaroxaban was found to have a benefit in older ( $\geq 65$ years) and elderly ( $\geq 75$ years) patients consistent with that seen in younger patients. ${ }^{24,40}$ This consistency was also reported in a subanalysis of the PLATO trial: there were no significant differences in the clinical benefit of ticagrelor over clopidogrel in patients with ACS aged $<75$ years and $\geq 75$ years $\left(P_{\text {interaction }}=0.56\right) .{ }^{38}$ However, results from a subanalysis of the TRILOGY ACS trial in patients not undergoing a revascularization procedure demonstrated a similar rate of multiple ischemic events with prasugrel and with clopidogrel (HR 1.03, 95\% CI 0.86-1.22; $P=0.73$ ) in patients $\geq 75$ years old. ${ }^{11,39,41}$

\section{Female sex}

Female sex is an independent predictor of major bleeding in ACS. Compared with men, women with ACS are generally older, have more comorbidities, are more likely to present with atypical symptoms, and have higher mortality rates. ${ }^{6,15,42}$ As can be expected, women also have a higher risk of recurrent ischemic events at 6 months than men (odds ratio 1.24, 95\% CI 1.14-1.34). ${ }^{14}$

Current guidelines recommend that men and women with ACS are managed in the same way. ${ }^{5,6}$ However, a study into the prevalence of adverse drug reactions associated with CAD therapies found that despite a similar occurrence of adverse drug reactions in men and women treated with ASA, women were significantly less likely than men to receive ASA (odds ratio $0.164,95 \%$ CI $0.083-0.322 ; P=0.001) .{ }^{15}$ This suggests the possible underuse of antiplatelet therapy in women compared with men, although the reasons for this are unclear.

Additionally, data from the long-term secondary ACSprevention trials suggest no significant difference in efficacy and safety outcomes between men and women. ${ }^{10,24,28-30}$ Results from the TRITON-TIMI 38 trial suggested a possible trend toward a reduced efficacy benefit with prasugrel versus clopidogrel in women (relative risk reduction [RRR] in the primary efficacy end point: males $21 \%$ versus females $12 \%) .{ }^{11}$ However, there was no indication from the published paper that this difference was statistically significant. Analyses of the PLATO study data have shown similar adverse cardiovascular outcomes and bleeding risks in women and men after adjustment for differences in baseline features, including age. ${ }^{43}$ Additionally, ticagrelor had a similar efficacy and safety profile in women and men. Collectively, the trial data suggest that sex-specific long-term secondary prevention strategies do not have a major effect on outcomes between female and male patients, suggesting that improved implementation of guideline recommendations is required in this patient population.

\section{Patients with elevated cardiac biomarkers}

Elevated cardiac biomarkers (creatine kinase MB and troponins) are indicative of myocardial tissue damage, and are associated with an increased risk of future ischemic events ${ }^{5}$ GRACE data show that elevated cardiac biomarkers are associated with a $70 \%$ increase in the risk of death or MI between hospital admission and 6-month follow-up (HR 1.7, 95\% CI 1.60-1.87). ${ }^{20}$ Therefore, early identification of this high-risk patient population is important to ensure the prompt use of guideline-recommended, evidence-based therapies.

Trial data have shown a greater impact of long-term antithrombotic therapy in patients with elevated cardiac biomarkers. In the PLATO trial, patients with elevated cardiac biomarkers showed a trend toward a greater benefit 


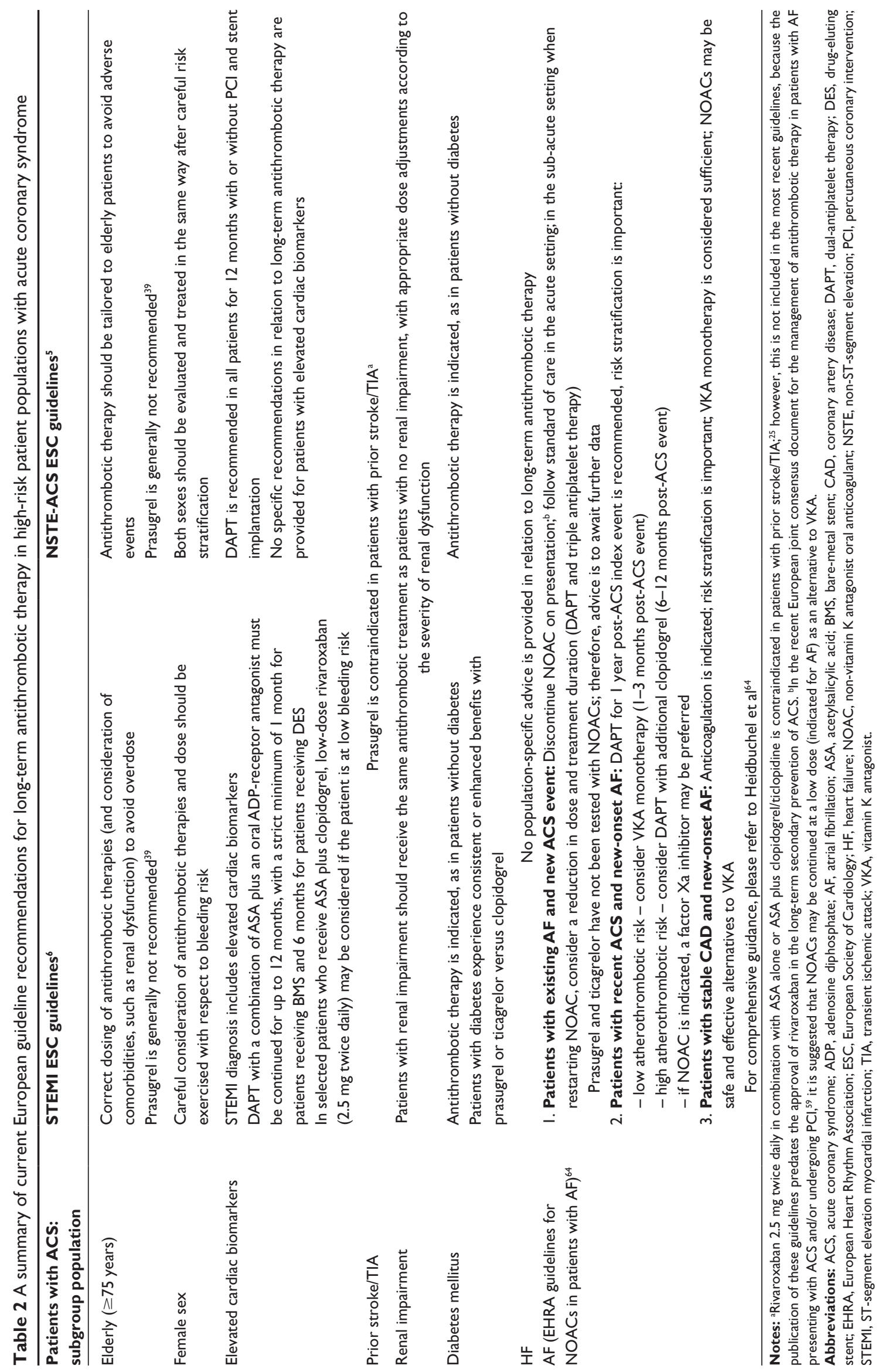


with ticagrelor versus clopidogrel for the primary efficacy end point: the composite of death from vascular causes, MI, or stroke (positive biomarker status, HR 0.85, 95\% CI 0.77-0.94; negative biomarker status, HR 1.00, 95\% CI 0.75-1.32). ${ }^{10}$ Additionally, a recent PLATO subanalysis evaluating the relationship between biomarkers and the effect of ticagrelor compared with clopidogrel in patients with NSTE-ACS found that elevated high-sensitivity troponin T (Hs-TnT) was a predictor of cardiovascular events in patients managed noninvasively. Elevated Hs-TnT compared with normal Hs-TnT also predicted a greater benefit of ticagrelor over clopidogrel in both invasively and noninvasively managed patients. ${ }^{44}$

Similarly, a post hoc analysis of the ATLAS ACS 2 TIMI 51 trial data also reported a greater net clinical benefit of rivaroxaban in combination with standard antiplatelet therapy in patients with elevated cardiac biomarkers (and without prior stroke/TIA). ${ }^{45}$ This formed the basis of the European Union approval of the rivaroxaban $2.5 \mathrm{mg}$ twice-daily dose. ${ }^{25}$ These results emphasize the important role biomarkers have in risk stratification and tailoring treatments to patients who will receive the greatest benefit.

\section{Patients with a history of prior stroke or transient ischemic attack}

Prior stroke/TIA is associated with an increased risk of bleeding. Prior vascular disease, defined as prior stroke or peripheral arterial disease, is an independent predictor of bleeding, and is a component of the CRUSADE risk-scoring scheme for major in-hospital bleeding. ${ }^{34}$ The significant bleeding risk associated with this high-risk patient population was also demonstrated in many of the antithrombotic Phase III clinical trials summarized in Table 1. ${ }^{10,11,24,28-31}$

Unlike other trials, such as ATLAS ACS 2 TIMI 51 (discussed herein), the PLATO trial did not exclude patients with a history of prior stroke/TIA and did not report a lack of efficacy benefit. ${ }^{10}$ A subanalysis of the PLATO trial investigating the impact of prior stroke/TIA on the effect of ticagrelor compared with clopidogrel found a relative reduction in the primary efficacy end point with ticagrelor compared with clopidogrel in patients with $(19.0 \%$ versus $20.8 \%$, HR $0.87,95 \%$ CI $0.66-1.13)$ and without $(9.2 \%$ versus $11.1 \%$, HR $0.84,95 \%$ CI $0.76-0.93$ ) prior stroke/ TIA $\left(P_{\text {interaction }}=0.84\right) .{ }^{46}$ Ticagrelor was not associated with an increased risk of PLATO-defined major bleeding events in patients with $(14.6 \%$ versus $14.9 \%$, HR 0.99 , 95\% CI $0.71-1.37$ ) or without (11.4\% versus $11.0 \%$, HR $1.04,95 \%$ CI $0.95-1.14)$ prior stroke/TIA $\left(P_{\text {interaction }}=0.77\right) .{ }^{46}$
However, a net clinical benefit analysis of the TRITONTIMI 38 data - which defined net clinical benefit as the rate of death from any cause, nonfatal MI, nonfatal stroke, or noncoronary artery bypass graft (CABG)-related nonfatal TIMI (Thrombolysis in Myocardial Infarction) major bleeding reported significant net clinical harm with prasugrel versus clopidogrel in patients with prior stroke/TIA (HR 1.54, 95\% CI 1.02-2.32; $P=0.04)$; this was driven by increased rates of major bleeding. ${ }^{11}$

In ATLAS ACS 2 TIMI 51, this high-risk patient population was included in Stratum 1 (rivaroxaban in combination with ASA) but excluded from Stratum 2 (rivaroxaban in combination with ASA plus thienopyridine: $93 \%$ of all patients). ${ }^{24}$ The decision to exclude these patients from Stratum 2 was based predominantly on the findings of the earlier TRITON-TIMI 38 trial. ${ }^{11}$ In Stratum 1, there was a trend suggesting that the efficacy benefit associated with rivaroxaban in the overall study population was not seen in patients with prior stroke/TIA (primary efficacy end point, HR 1.57, 95\% CI 0.75-3.31; Figure 2). ${ }^{24}$ Based on these findings, prasugrel and rivaroxaban $2.5 \mathrm{mg}$ twice daily are contraindicated in patients with a history of prior stroke or TIA. ${ }^{25,39}$

\section{Patients with renal impairment}

Renal function is generally categorized as normal (creatinine clearance $[\mathrm{CrCl}]$ rate $>60 \mathrm{~mL} / \mathrm{min})$, moderately impaired $(\mathrm{CrCl}$ $30-60 \mathrm{~mL} / \mathrm{min})$, or severely impaired $(\mathrm{CrCl}<30 \mathrm{~mL} / \mathrm{min})$. Renal impairment, which occurs in approximately $30 \%-40 \%$ of patients with $\mathrm{ACS},{ }^{6}$ is an independent predictor of increased long-term mortality and a major bleeding risk; it also has implications for dosing, because dose reductions may be required to avoid high drug exposure in patients with renal impairment. ${ }^{5,6}$

In patients with NSTE-ACS and severe renal impairment, the 30-day mortality rate and major bleeding rate are significantly higher (both $P<0.0001$ ) than in those with moderate impairment or normal function. ${ }^{12}$ Similarly, in patients with STEMI, both in-hospital and 6-month mortality rates increase with declining renal function (both $P<0.0001$ ). ${ }^{5}$ Despite the higher mortality rates in these patients, they are less likely to receive aggressive antithrombotic therapies and invasive treatment; this is possibly because of the risk of bleeding complications and potential drug overdose, given that the majority of these drugs are (to varying degrees) excreted via the kidneys. ${ }^{5}$

Clinical trials generally exclude patients with severe renal impairment, and are often adapted to include dose 
adjustments for patients with moderate renal impairment. ${ }^{34}$ In TRITON-TIMI 38, patients with $\mathrm{CrCl}<60 \mathrm{~mL} / \mathrm{min}$ did not seem to benefit from prasugrel therapy to the same degree as those with $\mathrm{CrCl} \geq 60 \mathrm{~mL} / \mathrm{min}$ (14\% RRR and 20\% RRR, respectively); the results of the study give no indication of any significant interaction between renal function and study treatment. ${ }^{11}$ A PLATO subanalysis investigated the impact of renal impairment on the effectiveness of ticagrelor. ${ }^{47}$ This study found that compared with clopidogrel, ticagrelor significantly reduced the primary efficacy end point in patients with chronic renal impairment $(\mathrm{CrCl}<60 \mathrm{~mL} / \mathrm{min}, 17.3 \%$ versus $22.0 \%$ [HR $0.77,95 \%$ CI $0.65-0.90]$ ), with a greater absolute risk reduction than in patients with normal renal function $(\mathrm{CrCl} \geq 60 \mathrm{~mL} / \mathrm{min} ; 7.9 \%$ versus $8.9 \%$ [HR 0.90 , 95\% CI 0.79-1.02; $\left.\left.P_{\text {interaction }}=0.13\right]\right)$. Renal function did not seem to affect the rates of TIMI non-CABG-related major bleeding associated with ticagrelor, compared with clopidogrel ( $\mathrm{CrCl} \geq 60 \mathrm{~mL} / \mathrm{min}$, HR 1.27, 95\% CI 0.97-1.67; $\left.\mathrm{CrCl}<60 \mathrm{~mL} / \mathrm{min}, \mathrm{HR} 1.28,95 \% \mathrm{CI} 0.88-1.85 ; P_{\text {interaction }}=0.98\right)$. There was no significant interaction between renal function and randomized treatment in any outcome variable. ${ }^{47}$

The results of ATLAS ACS 2 TIMI 51 do not show a significant impact of renal function on the relative efficacy of rivaroxaban (both doses combined) versus standard antiplatelet therapy alone (primary efficacy end point $\mathrm{CrCl} \geq 50 \mathrm{~mL} / \mathrm{min}$, HR 0.84, 95\% CI 0.73-0.96; $\mathrm{CrCl}<50 \mathrm{~mL} / \mathrm{min}, \mathrm{HR} 0.88$, $95 \%$ CI $\left.0.62-1.26 ; P_{\text {interaction }}=0.82\right) .{ }^{24}$ There was also no statistically significant effect of renal function on TIMI nonCABG-related major bleeding associated with rivaroxaban $2.5 \mathrm{mg}$ twice daily (both strata combined) versus standard antiplatelet therapy $(\mathrm{CrCl} \geq 50 \mathrm{~mL} / \mathrm{min}, \mathrm{HR} 3.21,95 \% \mathrm{CI}$ 1.89-5.46; $\mathrm{CrCl}<50$ mL/min, HR 7.60, 95\% CI 0.95-60.81; $\left.P_{\text {interaction }}=0.422\right) \cdot{ }^{48}$

Guidelines recommend caution when prescribing antithrombotic therapy for patients with renal impairment. Strategies to reduce the risk of bleeding must be employed, such as dose and treatment-duration adjustments, careful use of concomitant drugs, and the use of proton-pump inhibitors to reduce the risk of gastrointestinal bleeding. ${ }^{5,6,12}$

\section{Patients with diabetes mellitus}

Diabetes mellitus, which occurs in approximately 20\%-30\% of patients with ACS, ${ }^{5}$ is an independent predictor of death in these patients. It is associated with a poorer prognosis and a higher risk of acute MI, HF, and bleeding, both in the acute phase and in the long term. ${ }^{16} \mathrm{CAD}$ is the leading cause of death in patients with diabetes. ${ }^{16}$ The GRACE registry identified patients with diabetes as older, more likely to be female, and often presenting with atypical ACS symptoms, thus delaying diagnosis of ACS. ${ }^{5,16}$

Despite these recommendations, evidence-based therapies are underused in patients with diabetes and ACS. ${ }^{16,49}$ This underuse in patients with diabetes can be explained in part by the delay in presentation and diagnosis of ACS, as well as the increased risk of retinal hemorrhage and $\mathrm{ICH} .{ }^{16}$

A subanalysis of the PLATO trial found that compared with clopidogrel, ticagrelor reduced the rate of ischemic events irrespective of diabetic status without an increase in major bleeding. ${ }^{50}$ A subanalysis of the TRITON-TIMI 38 trial suggested that patients with diabetes seemed to receive a greater net clinical benefit from prasugrel compared with clopidogrel ( $14.6 \%$ versus $19.2 \%$, HR $0.74 ; P=0.001)$ than patients without diabetes $(11.5 \%$ versus $12.3 \%$, HR 0.92 ; $\left.P=0.160, P_{\text {interaction }}=0.05\right) .{ }^{51}$ In the ATLAS ACS 2 TIMI 51 rivaroxaban trial, there was also no significant interaction between treatment effect and diabetic status. ${ }^{24}$

The evidence suggests that patients with diabetes may benefit from improved implementation of guideline recommendations, which do not differentiate between patients with and without diabetes, for the use of antithrombotic therapy. $5,6,16$

\section{Patients with heart failure}

$\mathrm{HF}$ is one of the most serious complications of ACS, and is associated with a poorer prognosis than ACS without HF. Patients with ACS and HF are often older, more likely to be female, and more likely to have other comorbidities than patients with ACS but without HF. The presence or development of HF in the acute phase after an ACS event is also associated with a threefold increase in 6-month mortality rates $(8.5 \%$ versus $2.8 \% ; P<0.0001) .{ }^{52}$

The results of the CURE trial of ASA plus clopidogrel versus ASA alone in patients with NSTE-ACS suggested a trend toward a reduced efficacy benefit from clopidogrel in patients with HF compared with those without. ${ }^{30}$ Although firm conclusions cannot be drawn, the results of ATLAS ACS 2 TIMI 51 suggested that the relative efficacy of rivaroxaban $2.5 \mathrm{mg}$ twice daily (both strata combined) versus standard antiplatelet therapy alone was better in patients with a history of congestive HF (HR 0.58, 95\% CI 0.42-0.81) than in those without (HR 0.92, 95\% CI 0.77-1.09) $\left(P_{\text {interaction }}=0.016\right) .{ }^{48}$

\section{Patients with atrial fibrillation}

Preexisting or new-onset AF commonly complicates the management of ACS; patients with concomitant AF are often older, more likely to be female, and more likely to have 
other comorbidities than other patients with ACS. ${ }^{6,17}$ In the GRACE registry, $7.9 \%$ and $6.2 \%$ of patients had preexisting and new-onset AF, respectively. ${ }^{17}$ These patients were at higher risk of stroke, both in hospital and postdischarge, ${ }^{6}$ and had higher mortality and morbidity rates compared with patients with ACS but without AF (in-hospital death: no AF $4.6 \%$, new-onset AF $14.9 \%$, preexisting AF 9.1\%; $P<0.001$ for both new-onset and preexisting AF versus no AF). ${ }^{17} \mathrm{New}-$ onset AF was also found to be an independent predictor of in-hospital adverse events in patients with ACS. ${ }^{6,17,53}$

The presence of AF also causes confusion regarding the management of patients with ACS; patients with both conditions are less likely to receive evidence-based medical and invasive therapies than patients with ACS without AF. ${ }^{53}$ For example, patients with preexisting AF are less likely to receive ASA in hospital than patients without AF (preexisting AF 87.7\% versus no AF 95.0\%; P<0.001). ${ }^{17}$ Additionally, fewer patients with ACS and new-onset or preexisting AF received guideline-recommended clopidogrel in hospital than patients with ACS without AF (new-onset AF $28.7 \%$ versus no AF $36.5 \% ; P<0.001$; preexisting AF $26.1 \%$ versus no AF $36.5 \% ; P<0.001),{ }^{17}$ indicating underuse of antiplatelet therapy in this patient population, which will have a negative effect on long-term secondary prevention of ACS in this subgroup.

Because patients with AF may receive long-term oral anticoagulant (OAC) therapy, many patients with ACS and preexisting AF are likely to have been receiving vitamin K-antagonist (VKA) therapy, possibly for a considerable period of time, prior to their admission to hospital. Most current guidelines recommend triple therapy with DAPT (low-dose ASA plus clopidogrel) and oral anticoagulation in these patients, with the duration of triple-antithrombotic therapy kept to a minimum because of the associated increase in bleeding risk. ${ }^{5,6,54,55}$ Specific recommendations for patients undergoing PCI also vary depending on the patient's bleeding risk and type of implanted stent. Triple therapy is recommended for the first 6 months in patients with low or intermediate bleeding risk and for 4 weeks in those with high bleeding risk; this is followed by combined VKA and clopidogrel therapy for up to 12 months, and VKA therapy alone after 12 months. ${ }^{55}$

There are limited prospective clinical trial data on tripleantithrombotic therapy in patients with concomitant ACS and AF, particularly with regard to the newer antiplatelets (prasugrel and ticagrelor) and the NOACs (rivaroxaban, apixaban, dabigatran, and edoxaban). Recent Danish registry data confirmed the increase in bleeding risk reported with triple therapy. ${ }^{56}$
Neither the APPRAISE-2 nor the ATLAS ACS 2 TIMI 51 trials (of apixaban and rivaroxaban, respectively) included patients with AF or those with an ongoing need for a parenteral or oral anticoagulant. ${ }^{28,48}$ In a recent small-scale study into the use of triple therapy with VKA, ASA, and clopidogrel $(\sim 94 \%)$ or prasugrel $(\sim 6 \%)$ in patients who underwent PCI, the bleeding rate was found to be significantly worse in patients receiving prasugrel ${ }^{57}$ However, patients on prasugrel had a higher risk profile at baseline, and so further studies are required to evaluate this finding.

Investigations have been carried out or are ongoing to expand on the limited clinical trial data currently available in this field. The WOEST trial compared single (clopidogrel only) with dual (ASA plus clopidogrel) antiplatelet therapy in patients with AF on warfarin therapy undergoing PCI; results showed that the use of clopidogrel and warfarin without ASA was associated with a significant reduction in bleeding complications and a decrease in the rate of thrombotic events and cardiovascular mortality. ${ }^{58}$ This finding questions the need for ASA as part of a combined antiplatelet-anticoagulant treatment strategy. The recent European joint consensus document for the management of antithrombotic therapy in patients with AF presenting with ACS and/or undergoing PCI reports that based on the WOEST trial, omitting ASA after stent implantation in favor of an OAC plus clopidogrel alone in selected patients with AF at low risk of stent thrombosis or recurrent cardiac events could be considered. ${ }^{59}$

Identifying the appropriate duration of combined therapy has also been evaluated recently. Owing to the increased risk of bleeding with prolonged periods of triple therapy, the ISAR-TRIPLE trial investigated the use of triple therapy in 614 patients undergoing drug-eluting stent (DES) implantation with indication for an OAC, focusing on the duration of clopidogrel therapy ( 6 weeks or 6 months; patients randomized 1:1) in a triple-therapy regimen (ASA + OAC [VKA] + clopidogrel). ${ }^{60}$ The primary end points of death, MI, stent thrombosis, stroke, or TIMI major bleeding at 9 months were similar between the 6-week and 6-month triple-therapy treatment arms (HR 1.14, 95\% CI 0.68-1.91; $P=0.63$ ). The findings indicated that shortening the clopidogrel time frame to the 6-week duration did not yield significantly different results to the 6-month duration of triple therapy in patients with an indication for OAC therapy who were undergoing DES PCI, with no clear reduction in ischemic benefit or fewer bleeding episodes compared with the 6-month duration. ${ }^{60}$

In another recent study, the potential benefit of extending DAPT was investigated by comparing outcomes following 30 months of DAPT after DES implantation with 
outcomes after the standard recommended 12 months in 9,961 patients randomly assigned to continue thienopyridine (clopidogrel or prasugrel) treatment or placebo. ${ }^{61}$ This study found that compared with patients taking placebo, patients who continued thienopyridine treatment had reduced rates of coprimary end points, stent thrombosis (HR 0.29, 95\% CI $0.17-0.48 ; P<0.001)$, and major adverse cardiovascular and cerebrovascular events (HR 0.71, 95\% CI 0.59-0.85; $P<0.001)$; however, these patients experienced increased rates of moderate or severe bleeding $(2.5 \%$ versus $1.6 \%$; $P=0.001)$. These results suggest that there may be benefit but also harm associated with extending DAPT ${ }^{61}$ Further studies evaluating optimal drug combinations, duration of use, and individualized therapy are needed.

The PIONEER AF-PCI trial ${ }^{62}$ with rivaroxaban and the REDUAL-PCI trial ${ }^{63}$ with dabigatran etexilate will provide further insight into the safety of different antithrombotic strategies after PCI with stent placement in patients with nonvalvular AF. In PIONEER AF-PCI, one group of patients will receive rivaroxaban $2.5 \mathrm{mg}$ twice daily plus DAPT for 1,6 , or 12 months (an "ACS-type" regimen); patients in the 1 - and 6-month arms then receive rivaroxaban $15 \mathrm{mg}$ once daily plus ASA until the end of treatment at 12 months (an "AF-type" regimen). A second group will receive VKA treatment plus DAPT for 1, 6, or 12 months, followed by VKA plus ASA until the end of treatment (at 12 months). A third group will receive rivaroxaban $15 \mathrm{mg}$ once daily plus clopidogrel for 12 months. This study is due to complete in the spring of $2016 .{ }^{62}$ In REDUAL-PCI, patients with AF undergoing PCI with stenting will be randomized to one of three arms: dabigatran etexilate $110 \mathrm{mg}$ twice daily plus single-antiplatelet therapy (clopidogrel or ticagrelor); dabigatran etexilate $150 \mathrm{mg}$ twice daily plus single-antiplatelet therapy (clopidogrel or ticagrelor); or warfarin plus DAPT (clopidogrel or ticagrelor plus ASA). This study aims to show noninferiority of dabigatran etexilate (both doses) compared with warfarin for efficacy (death, MI, and stroke/systemic embolism) and safety (International Society on Thrombosis and Haemostasis major clinically relevant bleeding) outcomes, and is due to complete in the summer of $2017 .^{63}$

The European Heart Rhythm Association practical guide offers some guidance on the use of NOACs in: 1) patients with AF who experience an ACS event; 2) patients with recent ACS ( $<1$ year) and new-onset AF; and 3) patients with stable $\mathrm{CAD}$ (remote $\mathrm{ACS} \geq 1$ year) and new-onset AF (Table 2). ${ }^{64}$ Furthermore, the European joint consensus document (mentioned earlier) emphasizes the importance of risk stratification in patients with AF undergoing PCI, offering suggestions on how to reduce bleeding risk based on available evidence, such as the use of new-generation DESs (associated with reduced duration of antiplatelet therapy) and proton-pump inhibitors. The joint consensus document also recommends OAC continuation rather than switching or bridging, and identifies the need for further data on the new $\mathrm{P}_{2} \mathrm{Y}_{12}$ inhibitors in the context of triple therapy. ${ }^{59}$

\section{Potential reasons for the underuse of evidence-based guideline- recommended therapy}

Evidence suggests that guideline adherence in high-risk ACS populations is suboptimal. ${ }^{12-14,16,17,20,52}$ A key explanation for the underuse of evidence-based guideline-recommended antithrombotic therapies seems to be the increased risk of bleeding. ${ }^{5}$ Bleeding is the most frequent and serious nonischemic complication of ACS management, and is associated with adverse clinical outcomes and a high risk of death. ${ }^{5,6,34}$ The risk of bleeding is highest in the acute phase after an index ACS event, and can be exacerbated by many of the treatment strategies recommended by evidence-based guidelines, including DAPT, triple-antithrombotic therapy (in patients with ACS complicated by AF), and the use of aggressive invasive reperfusion strategies (in elderly patients, patients with diabetes mellitus, or patients with renal impairment). ${ }^{5,6}$

The definition and site of bleeding are relevant, because they influence what is considered an acceptable benefit-risk profile. For example, in ATLAS ACS 2 TIMI 51, rivaroxaban $2.5 \mathrm{mg}$ twice daily increased rates of non-CABG-related TIMI major bleeding (1.8\% versus $0.6 \%$, HR 3.46, 95\% CI $2.08-5.77 ; P<0.001)$ and ICH $(0.4 \%$ versus $0.2 \%$, HR 2.83, 95\% CI 1.02-7.86; $P=0.04$ ) compared with placebo; however, as the rate of fatal bleeding was not increased $(0.1 \%$ versus $0.2 \% ; P=0.45)$, the benefit-risk profile may be considered acceptable. ${ }^{24}$ Furthermore, in an additional analysis by Gibson et al that examined events of broadly similar clinical consequence (described as "fatal or irreversible" events: nonbleeding cardiovascular death; nonfatal MI and ischemic stroke; fatal hemorrhage and $\mathrm{ICH}$ ), it was found that compared with placebo, rivaroxaban $2.5 \mathrm{mg}$ twice daily treatment prevented eleven fatal or irreversible ischemic events for every fatal or irreversible bleeding event caused. ${ }^{65}$

In the APPRAISE-2 trial, apixaban (compared with placebo) $5 \mathrm{mg}$ twice daily was associated with an increased rate of TIMI major bleeding events $(2.4 \%$ versus $0.9 \%$, HR 2.59 , $95 \%$ CI $1.50-4.46 ; P=0.001)$ and intracranial bleeding. ${ }^{28}$ 
Because the increased risk of bleeding was not outweighed by a reduction in the risk of an ischemic event, the trial was terminated prematurely. The lack of efficacy benefit associated with apixaban can potentially be explained by two key differences between the APPRAISE-2 trial and the ATLAS ACS 2 TIMI 51 trial. Firstly, APPRAISE-2 used the same dose of apixaban as that indicated for stroke prevention in patients with nonvalvular AF (5 mg twice daily), whereas ATLAS ACS 2 TIMI 51 used a lower dose of rivaroxaban ( $5 \mathrm{mg}$ and $2.5 \mathrm{mg}$ twice daily) than that approved in this indication (20 mg). Secondly, the patient population of APPRAISE-2 had a higher bleeding risk than that of ATLAS ACS 2 TIMI 51, and included such patients as those with renal insufficiency $(\mathrm{CrCl}<20 \mathrm{~mL} / \mathrm{min})$ or with a history of stroke/TIA, whereas ATLAS ACS 2 TIMI 51 excluded such patients (eg, $\mathrm{CrCl}<30 \mathrm{~mL} / \mathrm{min}$, and specific to Stratum 2, patients with a history of a prior stroke/TIA). ${ }^{24,25,28,40}$

There is an inherent bleeding risk associated with more aggressive antithrombotic treatments; therefore, risk stratification and prevention of bleeding is a key consideration when determining a patient's treatment plan. ${ }^{5,6}$ Guideline recommendations exist to aid in the prevention of bleeding events. Principally, risk stratification using GRACE and CRUSADE risk scores can help to identify high-risk patient populations. Once these populations are identified, such factors as dose adjustment (eg, in patients with renal impairment), reduction in the duration of treatment, and careful concomitant use of antithrombotics in DAPT and triple-antithrombotic therapy can be considered. Other recommendations include the less aggressive use of invasive therapies, and if these therapies are deemed necessary, the choice of radial over femoral access (such as in elderly patients and patients with diabetes mellitus). Lastly, the use of proton-pump inhibitors could be considered for patients susceptible to spontaneous gastrointestinal bleeding (given that $50 \%$ of bleeding events are gastrointestinal). 5,6

If bleeding complications occur, strategies to control the hemorrhage must be implemented. In major and severe bleeding (gastrointestinal, retroperitoneal, or intracranial), the interruption and neutralization of antithrombotic therapy is recommended, unless the hemorrhage can be controlled through hemostatic measures. ${ }^{5,6}$ However, the interruption of antiplatelet and anticoagulant therapy increases the risk of ischemic events, particularly in patients with stent implantation. Therefore, after hemodynamic control is achieved, antithrombotic therapy can be adjusted (through dose, duration, and drug combinations) and reintroduced to help prevent a recurrent ischemic event without significantly increasing the risk of bleeding. ${ }^{5}$

\section{Conclusion}

Most patients with ACS have comorbidities and risk factors that greatly increase their risk of ischemic or bleeding events; therefore, assessing the patient's overall benefit-risk profile is vital when considering their long-term antithrombotictreatment strategy. Clinical data suggest that many different high-risk patient populations benefit from the different antiplatelet and anticoagulant regimens available, eg, new and more potent $\mathrm{P} 2 \mathrm{Y}_{12}$ inhibitors ticagrelor and prasugrel are available. In addition, the results of ATLAS ACS 2 TIMI 51 have led to the European approval of rivaroxaban $2.5 \mathrm{mg}$ twice daily in combination with ASA alone or ASA plus clopidogrel or ticlopidine in patients with ACS and elevated cardiac biomarkers and no history of prior stroke or TIA. $^{24,25}$ The use of triple-antithrombotic therapy with DAPT plus rivaroxaban $2.5 \mathrm{mg}$ twice daily is recommended in the recent STEMI guidelines for long-term secondary prevention in certain patients. ${ }^{6}$ In some specific cases (eg, patients with ACS and concomitant AF), data about the best long-term secondary prevention strategy are limited, and further clinical studies are needed.

Here, we have established that evidence-based guidelinerecommended therapies are often underused in high-risk patients, owing to fear of major bleeding events. Managing a major bleeding event successfully, should it occur, is vital in high-risk patient populations, and specific guidance on treating patients with ACS who experience such an event is available. ${ }^{5,6}$ A greater familiarity with and a better understanding of the guidelines will also improve implementation of evidence-based therapies and encourage individualized treatment. ${ }^{35}$ Simple algorithms for individualized antithrombotic treatment are also needed to aid clinicians in implementing new treatment strategies so that any efficacy benefit is balanced against bleeding risk.

The current clinical evidence suggests that further reductions in vascular events after ACS may be possible in clinical practice with increased adherence to guidelines, careful dose adjustment, and further studies on the management of high-risk patients.

\section{Acknowledgments}

The author would like to acknowledge Abigail Macleod, who provided editorial support with funding from Bayer HealthCare Pharmaceuticals and Janssen Scientific Affairs, LLC. 


\section{Disclosure}

$\mathrm{SH}$ has received scientific grants from Pfizer, Bristol-Myers Squibb, and AstraZeneca, and has attended advisory boards for Pfizer, Bristol-Myers Squibb, Boehringer Ingelheim, Bayer, and AstraZeneca.

\section{References}

1. Ruff CT, Braunwald E. The evolving epidemiology of acute coronary syndromes. Nat Rev Cardiol. 2011;8(3):140-147.

2. Fox KA, Carruthers KF, Dunbar DR, et al. Underestimated and underrecognized: the late consequences of acute coronary syndrome (GRACE UK-Belgian Study). Eur Heart J. 2010;31(22):2755-2764.

3. Goldberg RJ, Currie K, White K, et al. Six-month outcomes in a multinational registry of patients hospitalized with an acute coronary syndrome (the Global Registry of Acute Coronary Events [GRACE]). Am J Cardiol. 2004;93(3):288-293.

4. Odden MC, Coxson PG, Moran A, Lightwood JM, Goldman L, BibbinsDomingo K. The impact of the aging population on coronary heart disease in the United States. Am J Med. 2011;124(9):827-833.

5. Hamm CW, Bassand JP, Agewall S, et al. ESC guidelines for the management of acute coronary syndromes in patients presenting without persistent ST-segment elevation: the Task Force for the Management of Acute Coronary Syndromes (ACS) in Patients Presenting Without Persistent ST-Segment Elevation of the European Society of Cardiology (ESC). Eur Heart J. 2011;32(23):2999-3054.

6. Steg PG, James SK, Atar D, et al. ESC Guidelines for the management of acute myocardial infarction in patients presenting with ST-segment elevation: The Task Force on the management of ST-segment elevation acute myocardial infarction of the European Society of Cardiology (ESC). Eur Heart J. 2012;33(20):2569-2619.

7. Shanker J, Gasparyan AY, Kitas GD, Kakkar VV. Platelet function and antiplatelet therapy in cardiovascular disease: implications of genetic polymorphisms. Curr Vasc Pharmacol. 2011;9(4):479-489.

8. Gasparyan AY, Watson T, Lip GY. The role of aspirin in cardiovascular prevention: implications of aspirin resistance. J Am Coll Cardiol. 2008;51(19):1829-1843.

9. Aradi D, Storey RF, Komócsi A, et al. Expert position paper on the role of platelet function testing in patients undergoing percutaneous coronary intervention. Eur Heart J. 2014;35(4):209-215.

10. Wallentin L, Becker RC, Budaj A, et al. Ticagrelor versus clopidogrel in patients with acute coronary syndromes. $N$ Engl J Med. 2009; 361(11):1045-1057.

11. Wiviott $\mathrm{SD}$, Braunwald E, McCabe $\mathrm{CH}$, et al. Prasugrel versus clopidogrel in patients with acute coronary syndromes. $N$ Engl $J$ Med. 2007;357(20):2001-2015.

12. Collet JP, Montalescot G, Agnelli G, et al. Non-ST-segment elevation acute coronary syndrome in patients with renal dysfunction: benefit of low-molecular-weight heparin alone or with glycoprotein IIb/IIIa inhibitors on outcomes. The Global Registry of Acute Coronary Events. Eur Heart J. 2005;26(21):2285-2293.

13. Devlin G, Gore JM, Elliott J, et al. Management and 6-month outcomes in elderly and very elderly patients with high-risk non-ST-elevation acute coronary syndromes: the Global Registry of Acute Coronary Events. Eur Heart J. 2008;29(10):1275-1282.

14. Dey S, Flather MD, Devlin G, et al. Sex-related differences in the presentation, treatment and outcomes among patients with acute coronary syndromes: the Global Registry of Acute Coronary Events. Heart. 2009;95(1):20-26.

15. Enriquez JR, Pratap P, Zbilut JP, Calvin JE, Volgman AS. Women tolerate drug therapy for coronary artery disease as well as men do, but are treated less frequently with aspirin, beta-blockers, or statins. Gend Med. 2008;5(1):53-61.
16. Franklin K, Goldberg RJ, Spencer F, et al. Implications of diabetes in patients with acute coronary syndromes. The Global Registry of Acute Coronary Events. Arch Intern Med. 2004;164(13):1457-1463.

17. Mehta RH, Dabbous OH, Granger CB, et al. Comparison of outcomes of patients with acute coronary syndromes with and without atrial fibrillation. Am J Cardiol. 2003;92(9):1031-1036.

18. Windecker S, Kolh P, Alfonso F, et al. 2014 ESC/EACTS guidelines on myocardial revascularization: the Task Force on Myocardial Revascularization of the European Society of Cardiology (ESC) and the European Association for Cardio-Thoracic Surgery (EACTS) Developed with the special contribution of the European Association of Percutaneous Cardiovascular Interventions (EAPCI). Eur Heart J. 2014;35(37):2541-2619.

19. Rogers WJ, Frederick PD, Stoehr E, et al. Trends in presenting characteristics and hospital mortality among patients with ST elevation and non-ST elevation myocardial infarction in the National Registry of Myocardial Infarction from 1990 to 2006. Am Heart J. 2008;156(6):1026-1034.

20. Fox KA, Dabbous OH, Goldberg RJ, et al. Prediction of risk of death and myocardial infarction in the six months after presentation with acute coronary syndrome: prospective multinational observational study (GRACE). BMJ. 2006;333(7578):1091.

21. Andreotti F, Testa L, Biondi-Zoccai GG, Crea F. Aspirin plus warfarin compared to aspirin alone after acute coronary syndromes: an updated and comprehensive meta-analysis of 25,307 patients. Eur Heart J. 2006;27(5):519-526.

22. De Caterina R, Husted S, Wallentin L, et al. General mechanisms of coagulation and targets of anticoagulants (Section I). Position Paper of the ESC Working Group on Thrombosis - Task Force on Anticoagulants in Heart Disease. Thromb Haemost. 2013;109(4):569-579.

23. Ardissino D, Merlini PA, Bauer KA, et al. Coagulation activation and long-term outcome in acute coronary syndromes. Blood. 2003;102(8):2731-2735.

24. Mega JL, Braunwald E, Wiviott SD, et al. Rivaroxaban in patients with a recent acute coronary syndrome. $N$ Engl J Med. 2012;366(1): 9-19.

25. Bayer Pharma. Xarelto (rivaroxaban) [summary of product characteristics]. 2014. Available from: http://www.ema.europa.eu/docs/en_GB/ document_library/EPAR_-_Product_Information/human/000944/ WC500057108.pdf. Accessed October 3, 2014.

26. Oldgren J, Budaj A, Granger CB, et al. Dabigatran vs placebo in patients with acute coronary syndromes on dual antiplatelet therapy: a randomized, double-blind, phase II trial. Eur Heart J. 2011;32(22): 2781-2789.

27. Steg PG, Mehta SR, Jukema JW, et al. RUBY-1: a randomized, doubleblind, placebo-controlled trial of the safety and tolerability of the novel oral factor Xa inhibitor darexaban (YM150) following acute coronary syndrome. Eur Heart J. 2011;32(20):2541-2554.

28. Alexander JH, Lopes RD, James S, et al. Apixaban with antiplatelet therapy after acute coronary syndrome. $N$ Engl J Med. 2011;365(8): 699-708.

29. Roe MT, Armstrong PW, Fox KA, et al. Prasugrel versus clopidogrel for acute coronary syndromes without revascularization. NEngl JMed. 2012;367(14):1297-1309.

30. Yusuf S, Zhao F, Mehta SR, Chrolavicius S, Tognoni G, Fox KK. Effects of clopidogrel in addition to aspirin in patients with acute coronary syndromes without ST-segment elevation. $N$ Engl J Med. 2001;345(7):494-502.

31. Wallentin L, Wilcox RG, Weaver WD, et al. Oral ximelagatran for secondary prophylaxis after myocardial infarction: the ESTEEM randomised controlled trial. Lancet. 2003;362(9386):789-797.

32. Husted S, De Caterina R, Andreotti F, et al. Non-vitamin K antagonist oral anticoagulants (NOACs): no longer new or novel. Thromb Haemost. 2014;111(5):781-782.

33. Roe MT, Ohman EM. A new era in secondary prevention after acute coronary syndrome. $N$ Engl J Med. 2012;366(1):85-87. 
34. Bueno H, Fernández-Avilés F. Use of risk scores in acute coronary syndromes. Heart. 2012;98(2):162-168.

35. Bottorff MB, Nutescu EA, Spinler S. Antiplatelet therapy in patients with unstable angina and non-ST-segment-elevation myocardial infarction: findings from the CRUSADE national quality improvement initiative. Pharmacotherapy. 2007;27(8):1145-1162.

36. Alexander KP, Newby LK, Cannon CP, et al. Acute coronary care in the elderly, part I: Non-ST-segment-elevation acute coronary syndromes: a scientific statement for healthcare professionals from the American Heart Association Council on Clinical Cardiology: in collaboration with the Society of Geriatric Cardiology. Circulation. 2007;115(19):2549-2569.

37. Alexander KP, Newby LK, Armstrong PW, et al. Acute coronary care in the elderly, part II: ST-segment-elevation myocardial infarction: a scientific statement for healthcare professionals from the American Heart Association Council on Clinical Cardiology: in collaboration with the Society of Geriatric Cardiology. Circulation. 2007;115(19):2570-2589.

38. Husted S, James S, Becker RC, et al. Ticagrelor versus clopidogrel in elderly patients with acute coronary syndromes: a substudy from the prospective randomized PLATelet inhibition and patient Outcomes (PLATO) trial. Circ Cardiovasc Qual Outcomes. 2012;5(5):680-688.

39. Eli Lilly Netherlands. Efient (prasugrel) [summary of product characteristics]. 2014. Available from: http://www.ema.europa.eu/docs/en_GB/ document_library/EPAR_-_Product_Information/human/000984/ WC500021971.pdf. Accessed August 26, 2014.

40. US Food and Drug Administration. Rivaroxaban (Xarelto): Cardiovascular and Renal Drugs Advisory Committee. 2012. Available from: http://www.fda.gov/downloads/AdvisoryCommittees/CommitteesMeetingMaterials/Drugs/CardiovascularandRenalD rugsAdvisoryCommittee/UCM305922.pdf. Accessed September 26, 2014.

41. Roe MT, Goodman SG, Ohman M, et al. Elderly patients with acute coronary syndromes managed without revascularization. Insights into the safety of long-term dual antiplatelet therapy with reduceddose prasugrel versus standard-dose clopidogrel. Circulation. 2013;128(8):823-833.

42. Moscucci M, Fox KA, Cannon CP, et al. Predictors of major bleeding in acute coronary syndromes: the Global Registry of Acute Coronary Events (GRACE). Eur Heart J. 2003;24(20):1815-1823.

43. Husted S, James SK, Bach RG, et al. The efficacy of ticagrelor is maintained in women with acute coronary syndromes participating in the prospective, randomized, PLATelet inhibition and patient Outcomes (PLATO) trial. Eur Heart J. 2014;35(23):1541-1550.

44. Wallentin L, Lindholm D, Siegbahn A, et al. Biomarkers in relation to the effects of ticagrelor in comparison with clopidogrel in non-STelevation acute coronary syndrome patients managed with or without inhospital revascularization: a substudy from the Prospective Randomized Platelet Inhibition and Patient Outcomes (PLATO) trial. Circulation. 2014;129(3):293-303.

45. European Medicines Agency. Assessment report: Xarelto. 2013. Available from: http://www.ema.europa.eu/docs/en_GB/document_ library/EPAR___Assessment_Report___Variation/human/000944/ WC500144718.pdf. Accessed September 26, 2014.

46. James SK, Storey RF, Khurmi NS, et al. Ticagrelor versus clopidogrel in patients with acute coronary syndromes and a history of stroke or transient ischemic attack. Circulation. 2012;125(23):2914-2921.

47. James S, Budaj A, Aylward P, et al. Ticagrelor versus clopidogrel in acute coronary syndromes in relation to renal function: results from the Platelet Inhibition and Patient Outcomes (PLATO) trial. Circulation. 2010;122(11):1056-1067.

48. Food and Drug Administration. Rivaroxaban for reducing the risk of cardiovascular events (cardiovascular death, myocardial infarction and stroke) after acute coronary syndrome (ACS). 2012. Available from: http://www.fda.gov/downloads/AdvisoryCommittees/CommitteesMeetingMaterials/Drugs/CardiovascularandRenalDrugsAdvisoryCommittee/UCM304757.pdf. Accessed October 5, 2014.
49. Yan RT, Yan AT, Tan M, et al. Underuse of evidence-based treatment partly explains the worse clinical outcome in diabetic patients with acute coronary syndromes. Am Heart J. 2006;152(4):676-683.

50. James S, Angiolillo DJ, Cornel JH, et al. Ticagrelor vs clopidogrel in patients with acute coronary syndromes and diabetes: a substudy from the PLATelet inhibition and patient Outcomes (PLATO) trial. Eur Heart J. 2010;31(24):3006-3016.

51. Wiviott SD, Braunwald E, Angiolillo DJ, et al. Greater clinical benefit of more intensive oral antiplatelet therapy with prasugrel in patients with diabetes mellitus in the trial to assess improvement in therapeutic outcomes by optimizing platelet inhibition with prasugrel-Thrombolysis in Myocardial Infarction 38. Circulation. 2008;118(16):1626-1636.

52. Steg PG, Dabbous OH, Feldman LJ, et al. Determinants and prognostic impact of heart failure complicating acute coronary syndromes observations from the Global Registry of Acute Coronary Events (GRACE). Circulation. 2004;109(4):494-499.

53. Al Khdair D, Alshengeiti L, Elbarouni B, et al. Management and outcome of acute coronary syndrome patients in relation to prior history of atrial fibrillation. Can J Cardiol. 2012;28(4):443-449.

54. Camm AJ, Lip GY, De Caterina R, et al. 2012 Focused update of the ESC Guidelines for the management of atrial fibrillation: an update of the 2010 ESC Guidelines for the management of atrial fibrillation. Developed with the special contribution of the European Heart Rhythm Association. Eur Heart J. 2012;33(21):2719-2747.

55. Lip GY, Huber K, Andreotti F, et al. Antithrombotic management of atrial fibrillation patients presenting with acute coronary syndrome and/or undergoing coronary stenting: executive summary - a Consensus Document of the European Society of Cardiology Working Group on Thrombosis, endorsed by the European Heart Rhythm Association (EHRA) and the European Association of Percutaneous Cardiovascular Interventions (EAPCI). Eur Heart J. 2010;31(11):1311-1318.

56. Lamberts M, Olesen JB, Ruwald MH, et al. Bleeding after initiation of multiple antithrombotic drugs, including triple therapy, in atrial fibrillation patients following myocardial infarction and coronary intervention: a nationwide cohort study. Circulation. 2012;126(10):1185-1193.

57. Sarafoff N, Martischnig A, Wealer J, et al. Triple therapy with aspirin, prasugrel and vitamin $\mathrm{K}$ antagonists in patients with drug eluting stent implantation and an indication for oral anticoagulation. $J$ Am Coll Cardiol. 2013;61(20):2060-2066.

58. Dewilde WJ, Oirbans T, Verheugt FW, et al. Use of clopidogrel with or without aspirin in patients taking oral anticoagulant therapy and undergoing percutaneous coronary intervention: an open-label, randomised, controlled trial. Lancet. 2013;381(9872):1107-1115.

59. Lip GY, Windecker S, Huber K, et al. Management of antithrombotic therapy in atrial fibrillation patients presenting with acute coronary syndrome and/or undergoing percutaneous coronary or valve interventions: a joint consensus document of the European Society of Cardiology Working Group on Thrombosis, European Heart Rhythm Association (EHRA), European Association of Percutaneous Cardiovascular Interventions (EAPCI) and European Association of Acute Cardiac Care (ACCA) endorsed by the Heart Rhythm Society (HRS) and Asia-Pacific Heart Rhythm Society (APHRS). Eur Heart J. 2014;35(45):3155-3179.

60. Fiedler KA, Maeng M, Mehilli J, et al. Duration of triple therapy in patients requiring oral anticoagulation after drug-eluting stent implantation (ISAR-TRIPLE Trial). Transcatheter Cardiovascular Therapeutics (TCT). 2014. Available from: http://clinicaltrialresults. org/Slides/TCT\%202014/Sarafoff_ISARTRIPLE.pdf. Accessed January 07, 2015.

61. Mauri L, Kereiakes DJ, Yeh RW, et al. Twelve or 30 months of dual antiplatelet therapy after drug-eluting stents. $N$ Engl J Med. 2014;371(23): 2155-2166.

62. Janssen Scientific Affairs. A study exploring two strategies of rivaroxaban and one of oral vitamin $\mathrm{K}$ antagonist in patients with atrial fibrillation who undergo percutaneous coronary intervention (PIONEER AF-PCI). Available from: http://clinicaltrials.gov/ct2/show/NCT01830543. NLM identifier: NCT01830543. Accessed September 26, 2014. 
63. Boehringer Ingelheim. Evaluation of dual therapy with dabigatran vs triple therapy with warfarin in patients with AF that undergo a PCI with stenting (REDUAL-PCI). NLM identifier: NCT02164864. Available from: https://clinicaltrials.gov/ct2/show/NCT02164864. Accessed September 11, 2014.

64. Heidbuchel H, Verhamme P, Alings M, et al. European Heart Rhythm Association Practical Guide on the use of new oral anticoagulants in patients with non-valvular atrial fibrillation. Europace. 2013;15(5):625-651.
65. Gibson CM, Levitan B, Murphy SA, et al. A net clinical outcome analysis comparing fatal or irreversible ischemic and bleeding events in ATLAS ACS 2 - TIMI 51. Circulation. 2012;126:A13152.

Therapeutics and Clinical Risk Management

\section{Publish your work in this journal}

Therapeutics and Clinical Risk Management is an international, peerreviewed journal of clinical therapeutics and risk management, focusing on concise rapid reporting of clinical studies in all therapeutic areas, outcomes, safety, and programs for the effective, safe, and sustained use of medicines. This journal is indexed on PubMed Central, CAS,
EMBase, Scopus and the Elsevier Bibliographic databases. The manuscript management system is completely online and includes a very quick and fair peer-review system, which is all easy to use. Visit http://www.dovepress.com/testimonials.php to read real quotes from published authors.

Submit your manuscript here: http://www.dovepress.com/therapeutics-and-clinical-risk-management-journal 